Vol. 5, No. 3-4, 2019

\author{
Viktor Zakharov ${ }^{1}$, Ihor Kuzio ${ }^{2}$, Vitaliy Korendiy ${ }^{3}$, Petro Dmyterko ${ }^{4}$ \\ 1. ISKRA PJSC, Ukraine, Lviv, Vuletska Street 14, E-mail: vktzakharov@gmail.com \\ 2. Department of Mechanics and Automation Engineering, Lviv Polytechnic National University, \\ Ukraine, Lviv, S. Bandery Street 12, E-mail: ihor.v.kuzo@lpnu.ua \\ 3. Department of Mechanics and Automation Engineering, Lviv Polytechnic National University, \\ Ukraine, Lviv, S. Bandery Street 12, E-mail: vitaliy.nulp@ gmail.com \\ 4. Department of Mechanics and Automation Engineering, Lviv Polytechnic National University, \\ Ukraine, Lviv, S. Bandery Street 12, E-mail: dmyterko.petro@gmail.com
}

\title{
ANALYSIS AND IMPROVEMENT OF DESIGN DIAGRAMS AND MATHEMATICAL MODELS OF VIBRATORY LAPPING MACHINES
}

Received: August 19, 2019 / Revised: October 3, 2019 / Accepted: December 28, 2019

\section{(C) Zakharov V., Kuzio I., Korendiy V., Dmyterko P., 2019}

\begin{abstract}
Problem statement. The development of energy-efficient and high-performance vibratory lapping machines demands the improvement of their design diagrams and calculation techniques. Purpose. The main objectives of this research consist in detailed analysis of existent design diagrams and mathematical models of vibratory lapping machines; designing the three-mass hanger-type structures of such machines providing circular oscillations of laps; derivation of differential equations describing the motion of their oscillatory systems. Methodology. The technique of the research is based on fundamental concepts of engineering mechanics, strength of materials and theory of mechanical vibrations. Findings (results). The improved design diagrams of vibratory lapping machines with circular oscillations of laps are proposed and the corresponding differential equations describing the motion of the working elements are derived. Originality (novelty). The mathematical model of circular oscillations of the three-mass mechanical oscillatory system of vibratory lapping machine is developed. The possibilities of performing the double-side lapping of cylindrical and prismatic parts are considered. Practical value. The results of the performed investigations can be used during creating new designs and improving existent structures of vibratory finishing machines for lapping flat surfaces of cylindrical and prismatic parts. Scopes of further investigations. In further investigations, it is necessary to perform the numerical modelling of the system's motion using the derived differential equations, and to compare the obtained theoretical results with the results of experimental investigations.
\end{abstract}

Keywords: lapping, finishing treatment, vibratory machine, linear oscillations, circular oscillations, equations of motion, mathematical model, design diagram, oscillatory system.

\section{Introduction. Problem statement}

A lapping is a technological process of finishing treatment, during which there is performed a removal of stock from the surfaces with a help of abrasive materials placed on the working surfaces of the laps. The principal diagram of lapping flat surfaces is presented in Fig. 1. The abrasive grains 4 are located in binding liquid 5, which is placed between the treated surface of the part 1 and the surface of the lap 3 . The abrasive grains 4 are indented in the lap 3 surface, because it is made of softer material than the part 1 . During the relative movements of the lap 3 and the part 1, the abrasive grains remove stock 2 from the treated surface of the part 1. Physical and mechanical properties of the lapped surfaces are much improved than those after grinding. The departure from the necessary geometric shape can reach $0.1 \ldots 0.3 \mu \mathrm{m}$, and the roughness can be equal to $R z=0.05 \ldots 0.025 \mu \mathrm{m}$.

The lapping is one of the most energy-intensive and long-time technological processes. It allows to obtain the improved physical and chemical properties of the material being treated in comparison with the 
finishing surface grinding. Nevertheless, the designs of lapping machines, as well as the lapping technologies, are much more complicated than the grinding ones. That is why, the development of energyefficient and high-performance lapping machines demands the improvement of their design diagrams and calculation techniques in order to simplify and intensify the corresponding treatment.

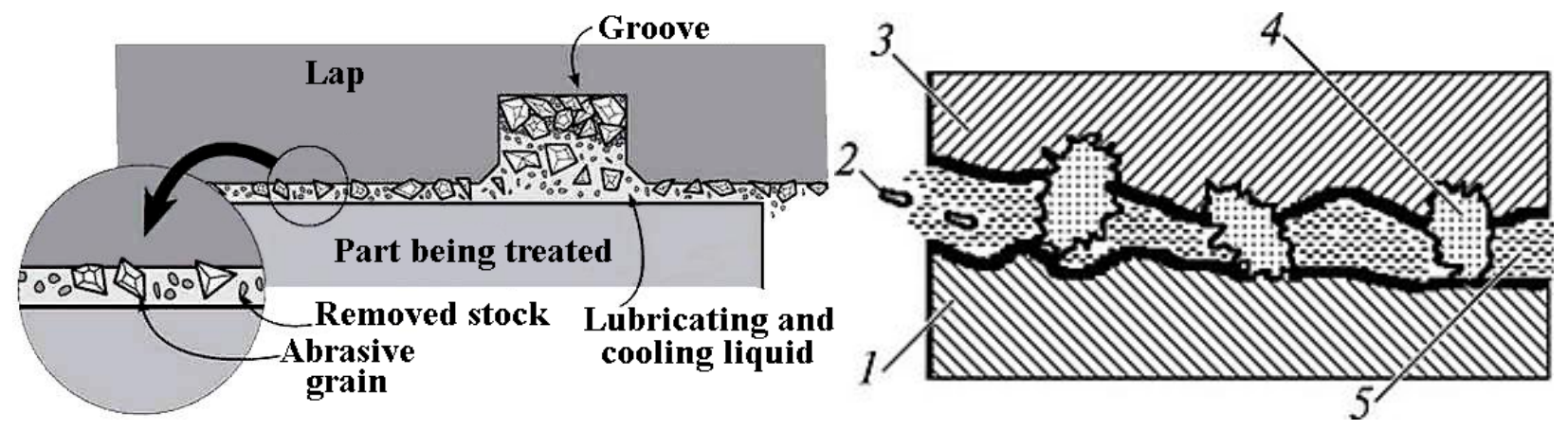

Fig. 1. Principal diagram of lapping process:

1 - part being treated; 2 - stock being removed; 3 - lap; 4 - abrasive grain; 5 - binding (cohesive) fluid

\section{Review of Modern Information Sources}

Numerous scientific publications are devoted to the problems of vibratory lapping and polishing of flat surfaces of machine parts. Most of the existent investigations covers the issues of straight-line (linear) oscillations of the working bodies [1]-[3]. This means that the technological process of lapping (polishing) is not considered as the planar (two-dimensional) one, and is reduced to the linear one. Therefore, the corresponding mathematical models describing the movements of the working bodies (laps) are sufficiently simplified and allow to easily derive the analytical dependencies for calculating the inertial, stiffness and excitation parameters of the machine's vibratory system in order to provide its operation in energy-efficient resonant mode.

In practice, most of vibratory lapping and polishing machines operate in two-dimensional coordinate system (usually, in horizontal plane). Some of such machines are considered in patents [4]-[7]. In the proposed designs, the finishing machines consist of three-mass oscillatory systems excited by electromagnetic drives. The parts to be treated are placed between the upper and the lower laps. The pushpull electromagnetic excitation is applied between the lower lap and the reactive masses. Depending on the excitation type, the laps can provide linear (straight-line) or planar (two-dimensional) movements.

Some of the lapping machines' designs have already been considered in papers [8]-[11]. Nevertheless, the papers [8]-[10] covers the issues of linear (straight-line) motion of the corresponding vibratory systems, and the paper [11] considers the process of dressing the laps, which provide planar (two-dimensional) motion (in particular, circular oscillations). In the present paper, there will be overviewed all the possible designs of single-mass, double-mass and three-mass vibratory systems of hanger-type lapping machines both with linear (straight-line) and planar (two-dimensional) movements of the working bodies (laps).

\section{Objectives and Problems of Research}

The main objective of this paper consists in thorough analysis of existent designs of hanger-type vibratory lapping machines. The corresponding mathematical models (differential equations) describing the motion of the machines' vibratory systems are to be formed and the analytical dependencies for calculating their inertial, stiffness and excitation parameters in order to provide the operation in energyefficient resonant mode are to be derived.

\section{Main Material Presentation}

Single-mass vibratory lapping machine with linear motion of lap (Fig. 2). In the presented design, the upper lap 1 performs straight-line vibrations, which provide the lapping of the upper flat surfaces of the parts 6 . The lap 1 can be freely placed on the surfaces of parts 6 or can be pressed by 
special devices. The straight-line excitation force $P(t)$ can be provided by electromagnetic, inertial or other type of vibration drive. The unmovable base 3 and the lower lap 4 form one rigid body 2 . The parts holding frame 7 is fixed on the base 3, and the lower surfaces of parts 6 contact with the lower lap 4 . The springs 5 ensure the oscillatory motion of the upper lap 1 under the action of excitation force $P(t)$.

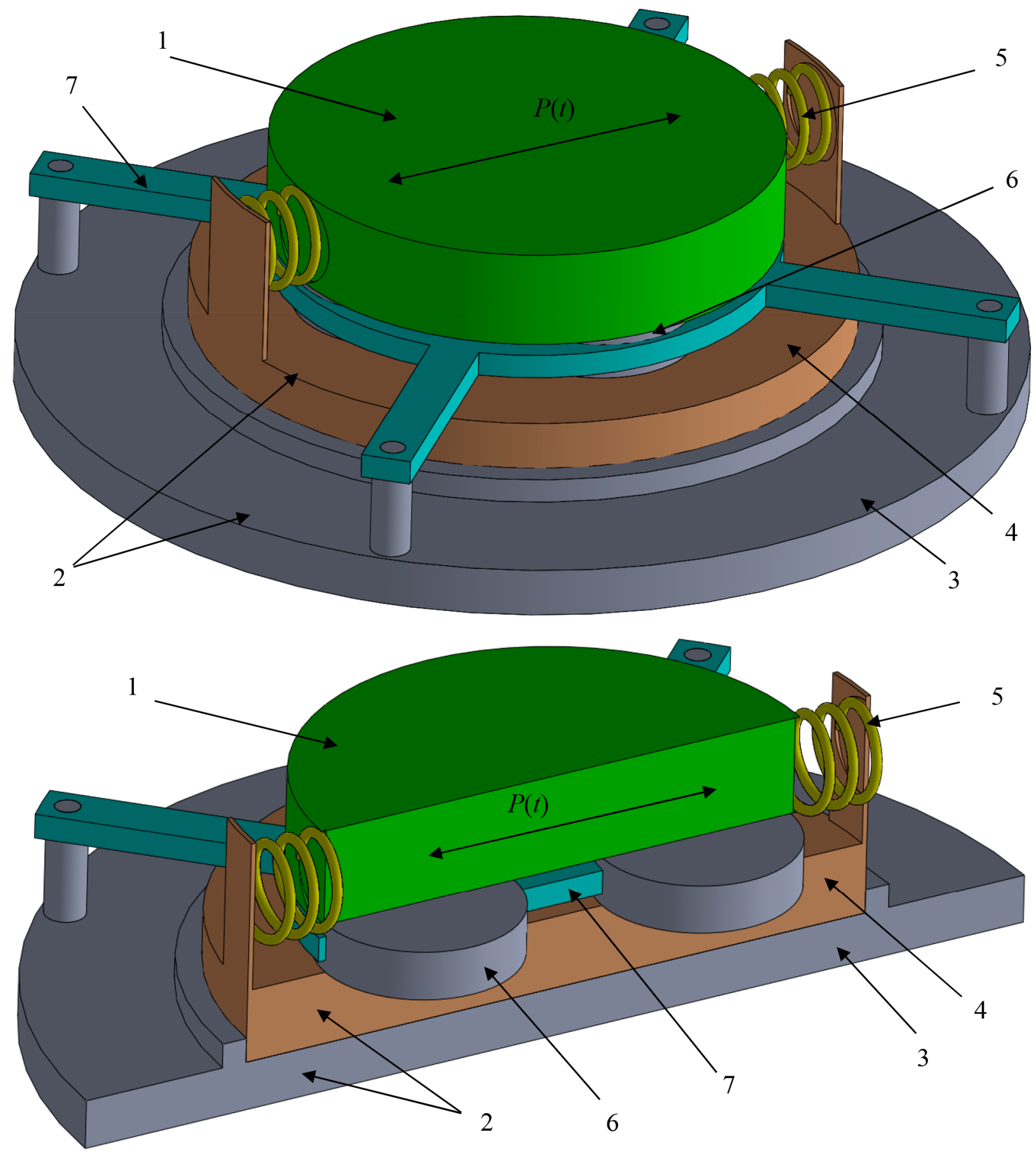

Fig. 2. Design diagram of single-mass vibratory lapping machine with linear motion of lap: 1 - upper lap; 2 - unmovable body; 3 - base; 4 - lower lap; 5 - spring; 6 - part; 7 - holding frame

Single-mass vibratory lapping machine with circular motion of lap (Fig. 3). In order to enlarge the possible duration of the lapping technological process without the necessity to dress the lap, as well as to improve the smoothness of the treated surface, it is proposed to provide circular oscillatory motion of the lap. This can be ensured by means of applying several forces (e.g., $\left.P_{1}(t), P_{2}(t), P_{3}(t)\right)$ of the same 


\section{Analysis and Improvement of Design Diagrams and Mathematical Models of Vibratory ...}

magnitude with the certain phase shift equal to $\pi / n$ (where $n$ is the number of applied forces). In this case, the lap 1 performs circular motion (circular oscillations) relative to the unmovable parts 6.
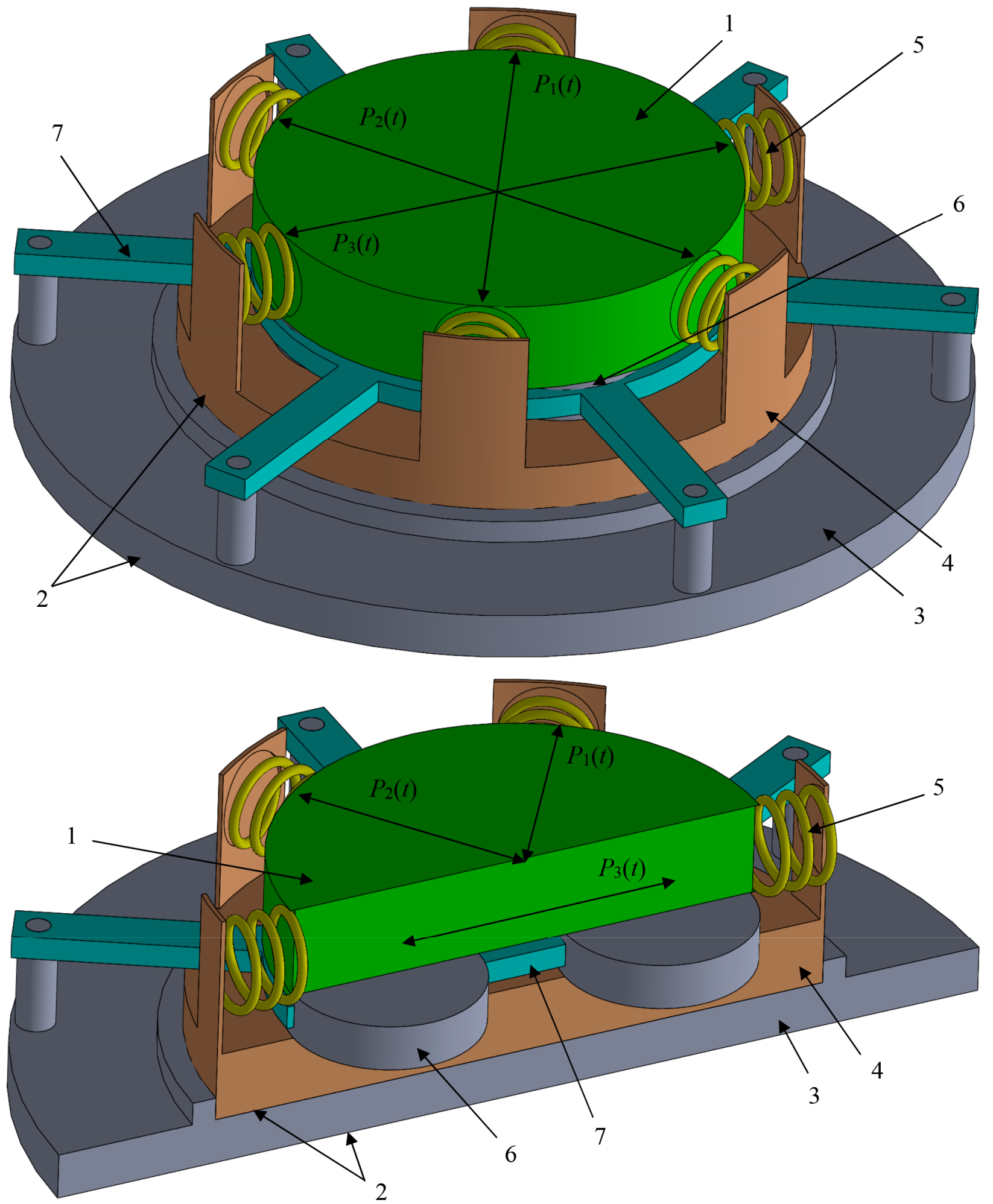

Fig. 3. Design diagram of single-mass vibratory lapping machine with circular motion of lap: 1 - upper lap; 2 - unmovable body; 3 - base; 4 - lower lap; 5 - spring; 6 - part; 7 - holding frame

Double-mass vibratory lapping machine with linear motion of laps (Fig. 4). Unlike single-mass vibratory lapping machine, the double-mass one provides the possibility of double-side lapping of flat surfaces of cylindrical or prismatic parts. The laps 1 and 2 can move relative to one another while the parts 
6 remain at rest. In order to decrease the energy losses in the lap's suspension (vibration isolation system), the hangers 4 are designed in the form of long ropes. This causes the necessity to redesign the machine's frame (body) 5. All the other design and operational peculiarities of the machine are similar to the single mass one with linear motion of the upper lap (see Fig. 2).

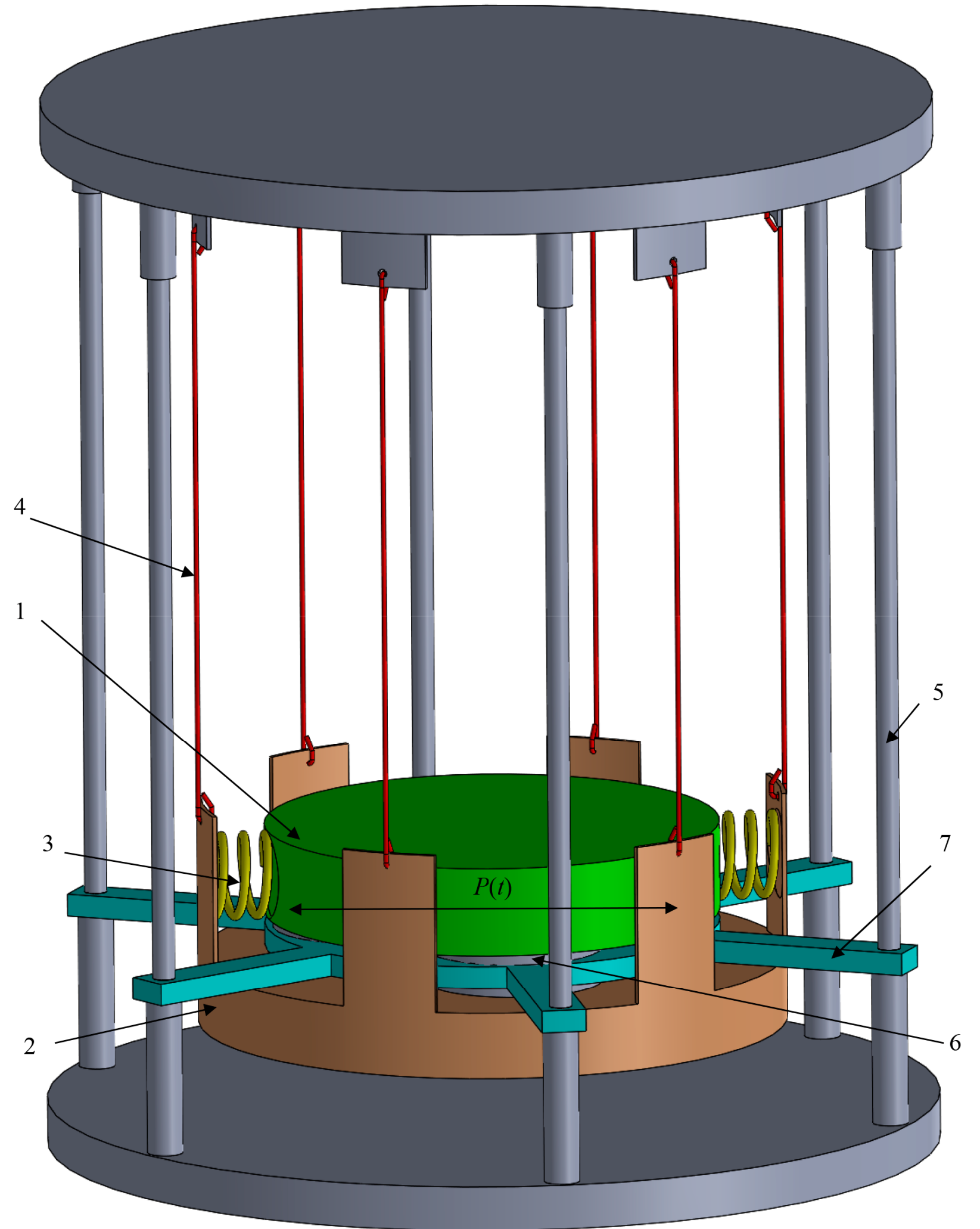

Fig. 4. Design diagram of double-mass vibratory lapping machine with linear motion of laps: 1 - upper lap; 2 - lower lap; 3 - spring; 4 - hanger (hanging rope); 5 - unmovable base (body); 6 - part; 7 - holding frame 
Double-mass vibratory lapping machine with circular motion of laps (Fig. 5). In this type of lapping machine, there is ensured the possibility of circular oscillatory motion of the upper and the lower laps. Several forces (e.g., $\left.P_{1}(t), P_{2}(t), P_{3}(t)\right)$ of the same magnitude with the certain phase shift equal to $\pi / n$ (where $n$ is the number of applied forces) are applied between the upper lap and the lower one. Therefore, the double-side lapping of flat surfaces of machine parts is performed.

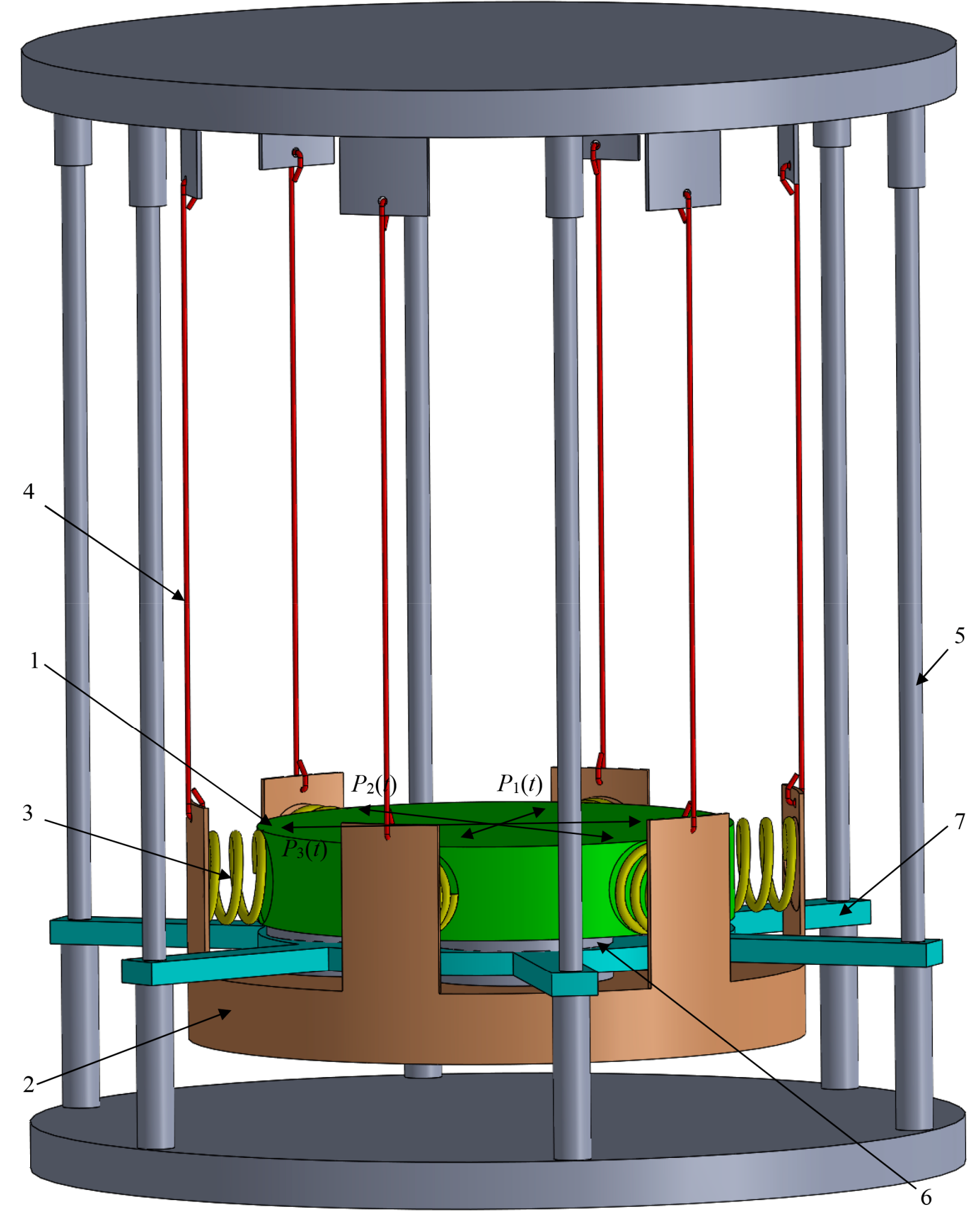

Fig. 5. Design diagram of double-mass vibratory lapping machine with circular motion of laps: 1 - upper lap; 2 - lower lap; 3 - spring; 4 - hanger (hanging rope); 5 - unmovable base (body); 6 - part; 7 - holding frame 
Three-mass vibratory lapping machine with linear motion of laps (Fig. 6). In the case of equipping the lapping machine by electromagnetic vibration exciters, there is a possibility to increase its efficiency ratio using a three-mass oscillatory system [1], [4]-[11]. The push-and-pull electromagnetic forces are applied between the reactive masses 8 and the lower lap 2. They excite the vibrations of the lower lap, which actuates the upper lap (sets it in linear oscillatory motion).

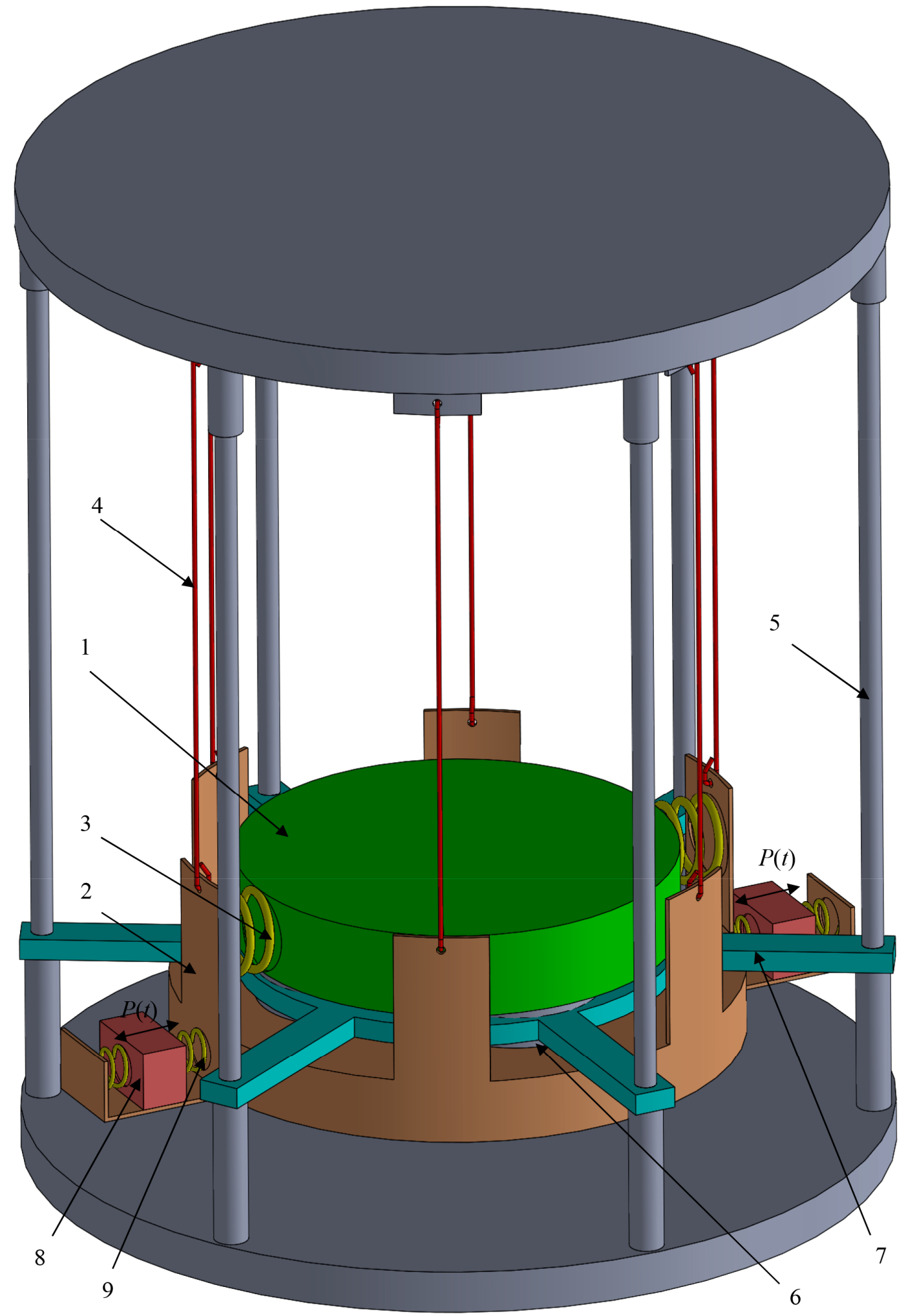

Fig. 6. Design diagram of three-mass vibratory lapping machine with linear motion of laps: 1 - upper lap; 2 - lower lap; 3, 9 - springs; 4 - hanger; 5 - unmovable base; 6 - part; 7 - holding frame; 8 - reactive mass 
Three-mass vibratory lapping machine with circular motion of laps (Fig. 7). This design combines the structural and operational peculiarities of double-mass machine with circular oscillatory motion of laps (see Fig. 5), and of the three-mass machine with application of excitation forces between the reactive masses and the lower lap (see Fig. 6).

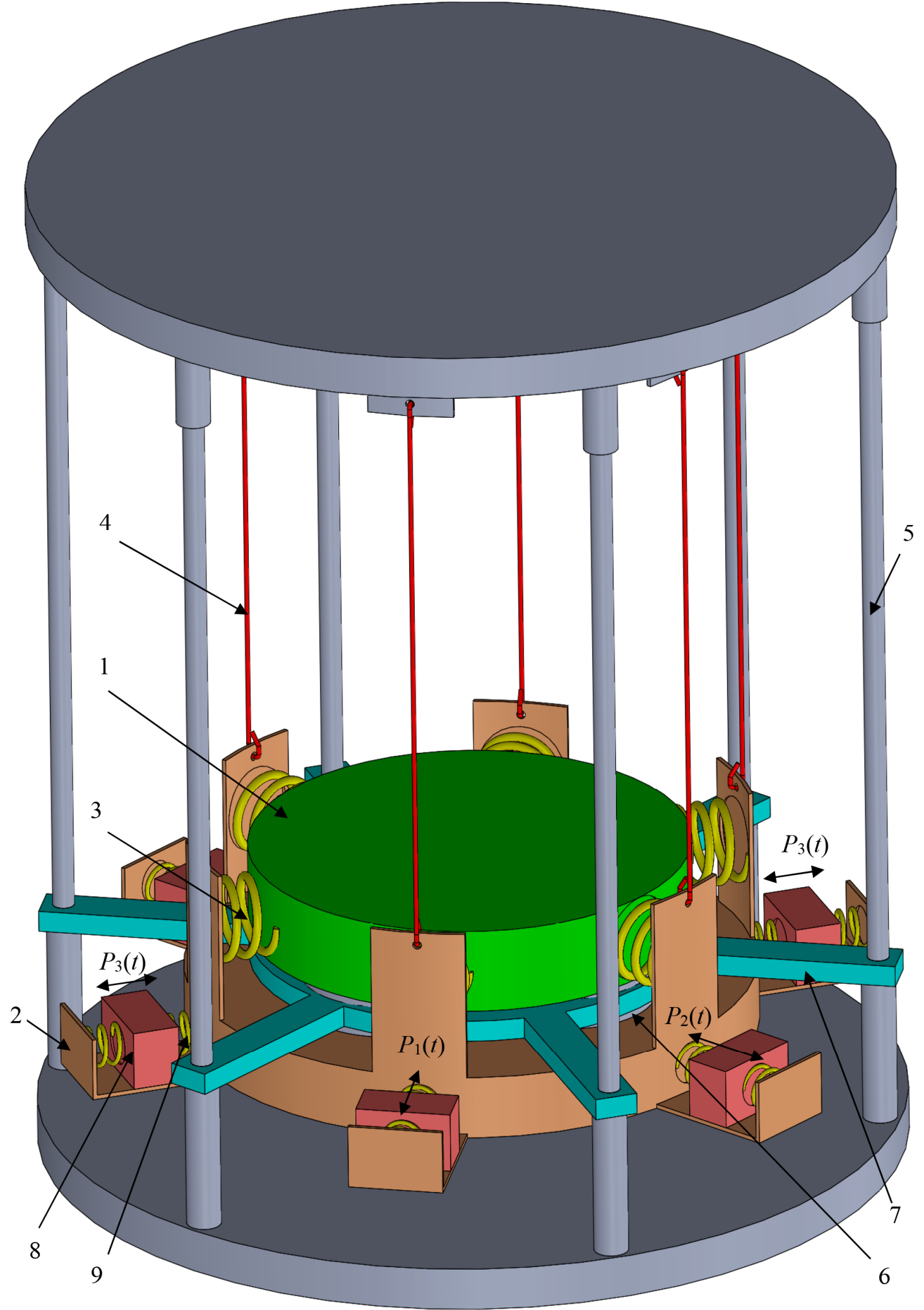

Fig. 7. Design diagram of three-mass vibratory lapping machine with circular motion of laps: 1 - upper lap; 2 - lower lap; 3, 9 - springs; 4 - hanger; 5 - unmovable base; 6 - part; 7 - holding frame; 8 - reactive mass 
Calculation models of oscillatory systems of vibratory lapping machines. The calculation models with linear (straight-line) oscillatory motion of laps are presented in Fig. 8. Considering the first model (Fig. 8,a), the upper lap is modelled as a rigid body of the mass $m_{1}$ lying on a rough horizontal surface. The oscillations are excited by force $P(t)$ and can be described by the coordinate $x_{1}$. The body's motion is restricted by a spring of stiffness $c_{1}$, which satisfies the conditions of the Hook's law. During the deformation of the spring, as well as during the body's motion, there occur the friction and damping processes causing the energy dissipation in the oscillatory system. The friction force is described by the coefficient $f_{v}$. The damping coefficient $\mu_{1}$ describes energy dissipation in the spring elements, and the damping coefficient $\mu_{v}$ describes the process of viscous friction between the surfaces of the lap and the treated parts, which is proportional to the lap's motion speed.

Considering the second model (Fig. 8, b), the upper and the lower laps are connected by the springs of stiffness $c_{1}$ and can move relative to one another. The upper lap lies on the top surfaces of the parts being treated, while the lower lap holds the parts and interacts with their lower (bottom) surfaces. The energy dissipation in the oscillatory system is described by friction coefficients $f_{v}, f_{l}$, and damping coefficients $\mu_{1}, \mu_{v}, \mu_{l}$. The lower lap is modelled as a rigid body of the mass $m_{2}$ hanged by the ropes. The treated parts are also considered as a rigid body of the total mass $m_{p}$. The excitation force $P(t)$ is applied between the laps. The oscillatory motion of the upper and the lower laps is described by the coordinates $x_{1}$ and $x_{2}$, respectively.

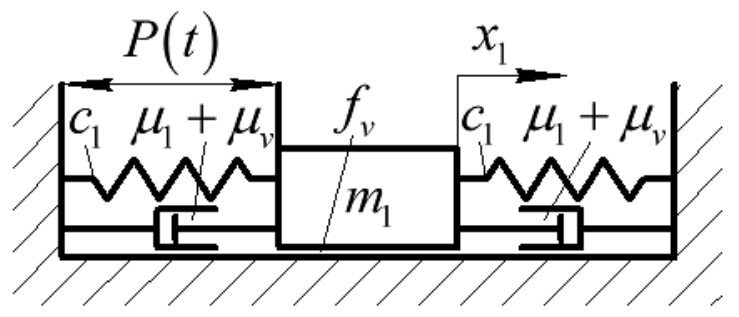

a

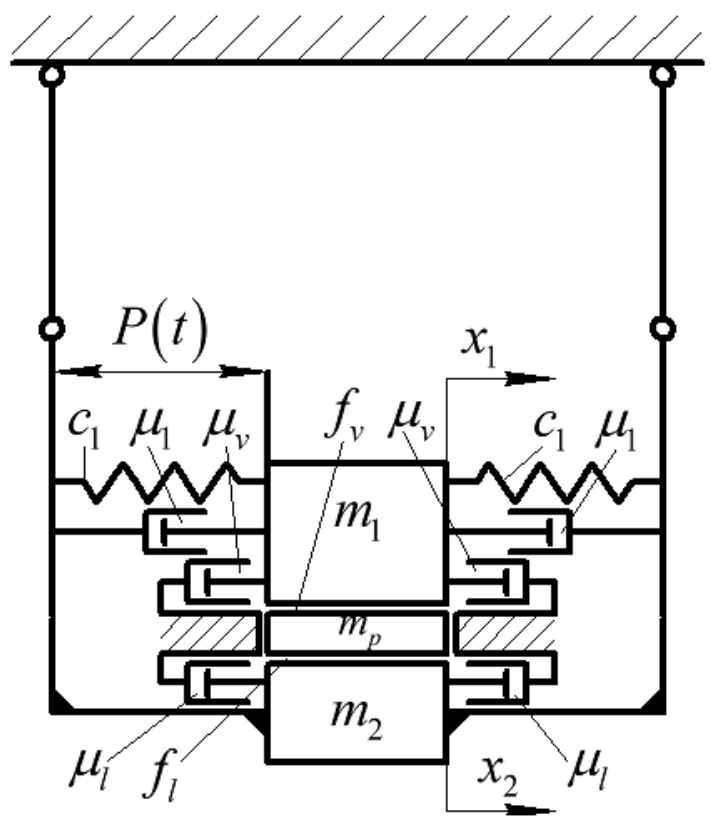

$\mathrm{b}$

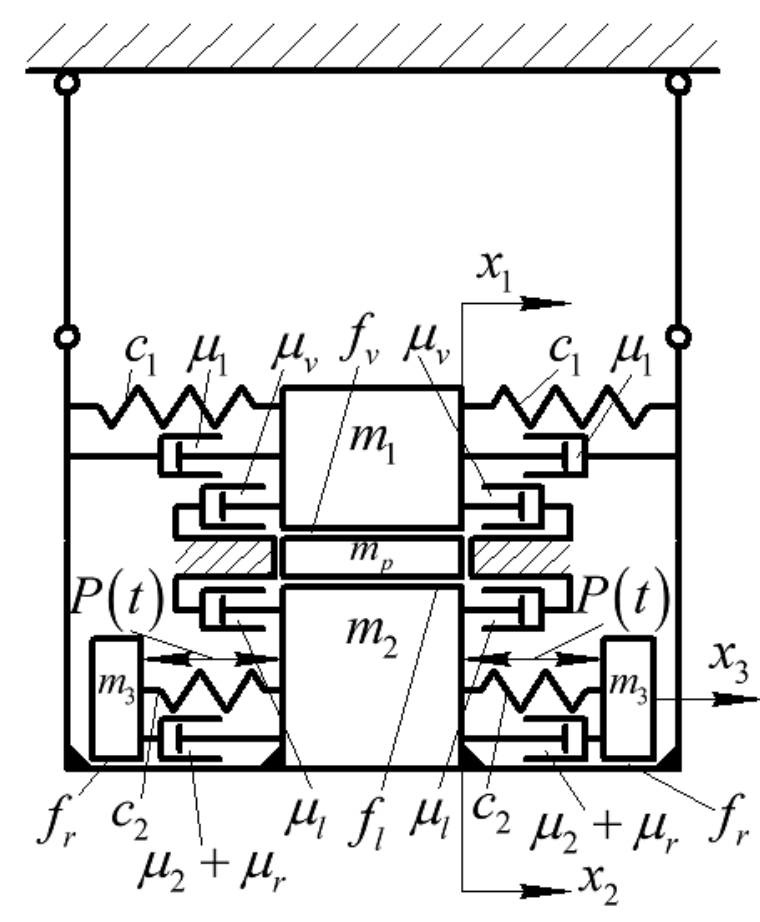

$\mathrm{c}$

Fig. 8. Calculation models of oscillatory systems of vibratory lapping machines with linear (straight-line) oscillatory motion of laps: $\mathrm{a}$ - single mass model: $\mathrm{b}$ - double-mass model; $\mathrm{c}$ - three-mass model 
In the third model (Fig. 8, $c$ ), the excitation forces $P(t)$ are applied between the lower lap and the reactive masses $m_{3}$, which are connected by the springs of stiffness $c_{2}$. The lower lap correspondingly sets the upper one in oscillatory motion. The reactive masses $m_{3}$ are modelled as rigid bodies able to slide over the lower lap. Thus, in this case, the corresponding coefficients of sliding friction $f_{r}$ and damping $\mu_{2}, \mu_{r}$ are considered. The damping coefficient $\mu_{2}$ describes energy dissipation in the spring elements between the lower lap and the reactive masses, and the damping coefficient $\mu_{r}$ describes the process of viscous friction between the surfaces of the lower lap and the sliding masses.

The models with circular motion of laps are not presented because of their significant complicity.

Differential equation of motion of single-mass oscillatory system with linear motion of lap (Fig. 2). The simplest model of oscillatory system of vibratory lapping machine (Fig. 2, Fig. 8, a) can be described by one homogeneous linear differential equation of the second order:

$$
m_{1} \cdot \ddot{x}_{1}+\left(\mu_{1}+\mu_{v}\right) \cdot \dot{x}_{1}+c_{1} \cdot x_{1}=P(t)-F_{f},
$$

where $P(t)$ can be considered as a periodic function (e.g., $P(t)=P \cdot \sin (\omega \cdot t) ; P$ is a magnitude of the periodic force; $\omega$ is a cyclic frequency of the periodic force); $F_{f}$ is a friction force between the contacting surfaces of the upper lap and the treated parts. In general, the friction force $F_{f}$ can be described by the following equation:

$$
F_{f}=f_{v} \cdot N \cdot \operatorname{sign}\left(\dot{x}_{1}\right)
$$

where $f$ is a coefficient of sliding friction depending on the materials and on the state of the upper lap's and the parts' contacting surfaces; $N$ is a normal reaction of the parts' surfaces caused by the action of the weight of the upper lap lying upon them $\left(N=m_{1} \cdot g\right) ; \operatorname{sign}\left(\dot{x}_{1}\right)$ is a function defining (specifying) the motion direction of the upper lap. It can be determined by the following formula:

$$
\operatorname{sign}\left(\dot{x}_{1}\right)=\left\{\begin{array}{l}
1, \text { if } \dot{x}_{1}>0 ; \\
-1, \text { if } \dot{x}_{1}<0 ; \\
0, \text { if } \quad \dot{x}_{1}=0 .
\end{array}\right.
$$

Therefore, taking into account formulas (2) and (3), the differential equation (1) can be written as:

$$
m_{1} \cdot \ddot{x}_{1}+\left(\mu_{1}+\mu_{v}\right) \cdot \dot{x}_{1}+c_{1} \cdot x_{1}=P \cdot \sin (\omega \cdot t)-f_{v} \cdot m_{1} \cdot g \cdot \operatorname{sign}\left(\dot{x}_{1}\right) .
$$

Differential equations of motion of single-mass oscillatory system with circular motion of lap (Fig. 3). Considering the second design of lapping machine (Fig. 3), it is necessary to describe the plane motion of the upper lap under the action of three periodic forces $\left.P_{1}(t), P_{2}(t), P_{3}(t)\right)$ of the same magnitude $P$ with the phase shift equal to $\pi / 3$ :

$$
\begin{gathered}
P_{1}(t)=P \cdot \sin (\omega \cdot t) ; \\
P_{2}(t)=P \cdot \sin (\omega \cdot t+\pi / 3) \\
P_{3}(t)=P \cdot \sin (\omega \cdot t+2 \cdot \pi / 3) .
\end{gathered}
$$

In the case of adopting plane Cartesian coordinate system, the lines of action of the corresponding forces must be projected on two perpendicular coordinate axes $x_{1}$ and $y_{1}$, where $x_{1}$ has the same direction as the force $P_{1}(t)$ does. Therefore, the differential equations describing the plane motion of the singlemass oscillatory system of vibratory lapping machine have the following form:

$$
\begin{gathered}
m_{1} \cdot \ddot{x}_{1}+\left(\mu_{1 x}+\mu_{v}\right) \cdot \dot{x}_{1}+c_{1 x} \cdot x_{1}= \\
=P \cdot \sin (\omega \cdot t)+P \cdot \sin (\omega \cdot t+\pi / 3) \cdot \cos (\pi / 3)+P \cdot \sin (\omega \cdot t+2 \cdot \pi / 3) \cdot \cos (2 \cdot \pi / 3)-f_{v} \cdot m_{1} \cdot g \cdot \operatorname{sign}\left(\dot{x}_{1}\right) ; \\
m_{1} \cdot \ddot{y}_{1}+\left(\mu_{1 y}+\mu_{v}\right) \cdot \dot{y}_{1}+c_{1 y} \cdot y_{1}= \\
=P \cdot \sin (\omega \cdot t+\pi / 3) \cdot \sin (\pi / 3)+P \cdot \sin (\omega \cdot t+2 \cdot \pi / 3) \cdot \sin (2 \cdot \pi / 3)-f_{v} \cdot m_{1} \cdot g \cdot \operatorname{sign}\left(\dot{y}_{1}\right),
\end{gathered}
$$


where $c_{1 x}=c_{1}+c_{1} \cdot \cos (\pi / 3)+c_{1} \cdot \cos (\pi / 3)=2 \cdot c_{1}$ is the reduced (projected on $x$-axis) stiffness of the springs connecting the upper and the lower laps; $c_{1 y}=c_{1} \cdot \sin (\pi / 3)+c_{1} \cdot \sin (\pi / 3)=1.732 \cdot c_{1}$ is the reduced (projected on $y$-axis) stiffness of the springs connecting the upper and the lower laps; $\mu_{1 x}=\mu_{1}+\mu_{1} \cdot \cos (\pi / 3)+\mu_{1} \cdot \cos (\pi / 3)=2 \cdot \mu_{1}$ is the reduced (projected on $x$-axis) damping coefficient of the springs connecting the upper and the lower laps; $\mu_{1 y}=\mu_{1} \cdot \sin (\pi / 3)+\mu_{1} \cdot \sin (\pi / 3)=1.732 \cdot \mu_{1}$ is the reduced (projected on $y$-axis) damping coefficient of the springs connecting the upper and the lower laps.

Differential equations of motion of double-mass oscillatory system with linear motion of laps (Fig. 4). The corresponding calculation model is presented in Fig. 8, $b$. The oscillations of the laps are performed relative to one another, while the friction forces act between the contacting surfaces of the laps and the parts being treated. If the coordinates $x_{1}$ and $x_{2}$ describe the motion of the upper and lower lap, respectively, so the differential equations of the system's motion can be written as follows:

$$
\begin{gathered}
m_{1} \cdot \ddot{x}_{1}+\mu_{v} \cdot \dot{x}_{1}+\mu_{1} \cdot\left(\dot{x}_{1}-\dot{x}_{2}\right)+c_{1} \cdot\left(x_{1}-x_{2}\right)=P \cdot \sin (\omega \cdot t)-f_{v} \cdot m_{1} \cdot g \cdot \operatorname{sign}\left(\dot{x}_{1}\right) ; \\
m_{2} \cdot \ddot{x}_{2}+\mu_{l} \cdot \dot{x}_{2}+\mu_{1} \cdot\left(\dot{x}_{2}-\dot{x}_{1}\right)+c_{1} \cdot\left(x_{2}-x_{1}\right)=-P \cdot \sin (\omega \cdot t)-f_{l} \cdot\left(m_{1}+m_{p}\right) \cdot g \cdot \operatorname{sign}\left(\dot{x}_{2}\right) .
\end{gathered}
$$

Differential equations of motion of double-mass oscillatory system with circular motion of laps (Fig. 5). Taking into account the design diagram presented in Fig. 5, it can be concluded that the diagram looks like the combination of the single-mass on with circular oscillations of the upper lap, and the doublemass one with linear oscillations of the upper and the lower lap. Therefore, it is necessary to adopt four independent variables $x_{1}, x_{2}, y_{1}$ and $y_{2}$ to describe the plane motion of the laps. In this case, the system of differential equations describing the laps' motion can be written as follows:

$$
\begin{gathered}
m_{1} \cdot \ddot{x}_{1}+\mu_{v} \cdot \dot{x}_{1}+\mu_{1 x} \cdot\left(\dot{x}_{1}-\dot{x}_{2}\right)+c_{1 x} \cdot\left(x_{1}-x_{2}\right)= \\
=P \cdot \sin (\omega \cdot t)+P \cdot \sin (\omega \cdot t+\pi / 3) \cdot \cos (\pi / 3)+P \cdot \sin (\omega \cdot t+2 \cdot \pi / 3) \cdot \cos (2 \cdot \pi / 3)-f_{v} \cdot m_{1} \cdot g \cdot \operatorname{sign}\left(\dot{x}_{1}\right) ; \\
m_{1} \cdot \ddot{y}_{1}+\mu_{v} \cdot \dot{y}_{1}+\mu_{1 y} \cdot\left(\dot{y}_{1}-\dot{y}_{2}\right)+c_{1 y} \cdot\left(y_{1}-y_{2}\right)= \\
=P \cdot \sin (\omega \cdot t+\pi / 3) \cdot \sin (\pi / 3)+P \cdot \sin (\omega \cdot t+2 \cdot \pi / 3) \cdot \sin (2 \cdot \pi / 3)-f_{v} \cdot m_{1} \cdot g \cdot \operatorname{sign}\left(\dot{y}_{1}\right) ; \\
m_{2} \cdot \ddot{x}_{2}+\mu_{l} \cdot \dot{x}_{2}+\mu_{1 x} \cdot\left(\dot{x}_{2}-\dot{x}_{1}\right)+c_{1 x} \cdot\left(x_{2}-x_{1}\right)=-P \cdot \sin (\omega \cdot t)- \\
-P \cdot \sin (\omega \cdot t+\pi / 3) \cdot \cos (\pi / 3)-P \cdot \sin (\omega \cdot t+2 \cdot \pi / 3) \cdot \cos (2 \cdot \pi / 3)-f_{l} \cdot\left(m_{1}+m_{p}\right) \cdot g \cdot \operatorname{sign}\left(\dot{x}_{2}\right) ; \\
m_{2} \cdot \ddot{y}_{2}+\mu_{l} \cdot \dot{y}_{2}+\mu_{1 y} \cdot\left(\dot{y}_{2}-\dot{y}_{1}\right)+c_{1 y} \cdot\left(y_{2}-y_{1}\right)= \\
=-P \cdot \sin (\omega \cdot t+\pi / 3) \cdot \sin (\pi / 3)-P \cdot \sin (\omega \cdot t+2 \cdot \pi / 3) \cdot \sin (2 \cdot \pi / 3)-f_{l} \cdot\left(m_{1}+m_{p}\right) \cdot g \cdot \operatorname{sign}\left(\dot{y}_{2}\right) .
\end{gathered}
$$

Differential equations of motion of three-mass oscillatory system with linear motion of laps (Fig. 6). In the considered case, the excitation force is applied between the reactive masses and the lower lap connected to each other by the springs. It is assumed that both reactive masses move synchronously (at one phase), so the mass $m_{3}$ will be considered as the total mass of two disturbing bodies, and the coordinate $x_{3}$ describes the motion of the bodies. The energy dissipation during the reactive masses motion relative to the lower lap is described by one sliding friction coefficient $f_{r}$ and two damping coefficients $\mu_{2}$ (energy dissipation in the springs) and $\mu_{r}$ (viscous friction during the reactive mass sliding). The motion of the oscillatory system can be modelled by the following differential equations:

$$
\begin{gathered}
m_{1} \cdot \ddot{x}_{1}+\mu_{v} \cdot \dot{x}_{1}+\mu_{1} \cdot\left(\dot{x}_{1}-\dot{x}_{2}\right)+c_{1} \cdot\left(x_{1}-x_{2}\right)=-f_{v} \cdot m_{1} \cdot g \cdot \operatorname{sign}\left(\dot{x}_{1}\right) ; \\
m_{1} \cdot \ddot{y}_{1}+\mu_{v} \cdot \dot{y}_{1}+\mu_{1} \cdot\left(\dot{y}_{1}-\dot{y}_{2}\right)+c_{1} \cdot\left(y_{1}-y_{2}\right)=-f_{v} \cdot m_{1} \cdot g \cdot \operatorname{sign}\left(\dot{y}_{1}\right) ; \\
m_{2} \cdot \ddot{x}_{2}+\mu_{l} \cdot \dot{x}_{2}+\mu_{1} \cdot\left(\dot{x}_{2}-\dot{x}_{1}\right)+\left(\mu_{2}+\mu_{r}\right) \cdot\left(\dot{x}_{2}-\dot{x}_{3}\right)+c_{1} \cdot\left(x_{2}-x_{1}\right)+c_{2} \cdot\left(x_{2}-x_{3}\right)=-P \cdot \sin (\omega \cdot t)- \\
-P \cdot \sin (\omega \cdot t+\pi / 3) \cdot \cos (\pi / 3)-P \cdot \sin (\omega \cdot t+2 \cdot \pi / 3) \cdot \cos (2 \cdot \pi / 3)- \\
-f_{l} \cdot\left(m_{1}+m_{p}\right) \cdot g \cdot \operatorname{sign}\left(\dot{x}_{2}\right)-f_{r} \cdot m_{3} \cdot g \cdot \operatorname{sign}\left(\dot{x}_{2}-\dot{x}_{3}\right) ;
\end{gathered}
$$




$$
\begin{gathered}
m_{2} \cdot \ddot{y}_{2}+\mu_{l} \cdot \dot{y}_{2}+\mu_{1} \cdot\left(\dot{y}_{2}-\dot{y}_{1}\right)+\left(\mu_{2}+\mu_{r}\right) \cdot\left(\dot{y}_{2}-\dot{y}_{3}\right)+c_{1} \cdot\left(y_{2}-y_{1}\right)+c_{2} \cdot\left(y_{2}-y_{3}\right)= \\
=-P \cdot \sin (\omega \cdot t+\pi / 3) \cdot \sin (\pi / 3)-P \cdot \sin (\omega \cdot t+2 \cdot \pi / 3) \cdot \sin (2 \cdot \pi / 3)- \\
-f_{l} \cdot\left(m_{1}+m_{p}\right) \cdot g \cdot \operatorname{sign}\left(\dot{y}_{1}\right)-f_{r} \cdot m_{3} \cdot g \cdot \operatorname{sign}\left(\dot{y}_{2}-\dot{y}_{3}\right) ; \\
m_{3} \cdot \ddot{x}_{3}+\left(\mu_{2}+\mu_{r}\right) \cdot\left(\dot{x}_{3}-\dot{x}_{2}\right)+c_{2} \cdot\left(x_{3}-x_{2}\right)=P \cdot \sin (\omega \cdot t)+ \\
+P \cdot \sin (\omega \cdot t+\pi / 3) \cdot \cos (\pi / 3)+P \cdot \sin (\omega \cdot t+2 \cdot \pi / 3) \cdot \cos (2 \cdot \pi / 3)-f_{r} \cdot m_{3} \cdot g \cdot \operatorname{sign}\left(\dot{x}_{3}-\dot{x}_{2}\right) ; \\
m_{3} \cdot \ddot{y}_{3}+\left(\mu_{2}+\mu_{r}\right) \cdot\left(\dot{y}_{3}-\dot{y}_{2}\right)+c_{2} \cdot\left(y_{3}-y_{2}\right)= \\
=P \cdot \sin (\omega \cdot t+\pi / 3) \cdot \sin (\pi / 3)+P \cdot \sin (\omega \cdot t+2 \cdot \pi / 3) \cdot \sin (2 \cdot \pi / 3)-f_{r} \cdot m_{3} \cdot g \cdot \operatorname{sign}\left(\dot{y}_{3}-\dot{y}_{2}\right) .
\end{gathered}
$$

Differential equations of motion of three-mass oscillatory system with circular motion of laps (Fig. 7). The considered design of the machine consists of six reactive (disturbing) masses evenly distributed in a circle. It is assumed that each pair of diametrically placed masses moves synchronously (at one phase), so the masses $m_{31}, m_{32}$ and $m_{33}$ will be considered as the total masses of the corresponding pairs of disturbing bodies. The oscillatory motion of the upper and the lower laps (masses $m_{1}$ and $m_{2}$, respectively) is described by the corresponding generalized coordinates $x_{1}, y_{1}$ and $x_{2}, y_{2}$, which represent the displacements of the mass centres of the upper and lower laps with respect to their equilibrium position. The mass centres' displacements of each pair of the reactive bodies are described by the generalized coordinates $x_{31}, x_{32}, x_{33}, y_{31}, y_{32}, y_{33}$. We assume that $y_{31}=y_{2}$ because the mass center of the first pair of reactive bodies cannot move along $y$-axis relative to the lower lap. Therefore, the differential equations of the three-mass system's motion are as follows:

$$
\begin{aligned}
& m_{1} \cdot \ddot{x}_{1}+\mu_{v} \cdot \dot{x}_{1}+\mu_{1 x} \cdot\left(\dot{x}_{1}-\dot{x}_{2}\right)+c_{1 x} \cdot\left(x_{1}-x_{2}\right)=-f_{v} \cdot m_{1} \cdot g \cdot \operatorname{sign}\left(\dot{x}_{1}\right) \\
& m_{1} \cdot \ddot{y}_{1}+\mu_{v} \cdot \dot{y}_{1}+\mu_{1 y} \cdot\left(\dot{y}_{1}-\dot{y}_{2}\right)+c_{1 y} \cdot\left(y_{1}-y_{2}\right)=-f_{v} \cdot m_{1} \cdot g \cdot \operatorname{sign}\left(\dot{y}_{1}\right) ; \\
& m_{2} \cdot \ddot{x}_{2}+\mu_{l} \cdot \dot{x}_{2}+\mu_{1 x} \cdot\left(\dot{x}_{2}-\dot{x}_{1}\right)+\mu_{r} \cdot\left(3 \cdot \dot{x}_{2}-\dot{x}_{31}-\dot{x}_{32}-\dot{x}_{33}\right)+ \\
& +\mu_{2} \cdot\left(\left(\dot{x}_{2}-\dot{x}_{31}\right)+\cos (\pi / 3) \cdot\left(2 \cdot \dot{x}_{2}-\dot{x}_{32}-\dot{x}_{33}\right)\right)+ \\
& +c_{1 x} \cdot\left(x_{2}-x_{1}\right)+c_{2} \cdot\left(\left(x_{2}-x_{31}\right)+\cos (\pi / 3) \cdot\left(2 \cdot x_{2}-x_{32}-x_{33}\right)\right)=-P \cdot \sin (\omega \cdot t)- \\
& -P \cdot \sin (\omega \cdot t+\pi / 3) \cdot \cos (\pi / 3)-P \cdot \sin (\omega \cdot t+2 \cdot \pi / 3) \cdot \cos (2 \cdot \pi / 3)- \\
& -f_{l} \cdot\left(m_{1}+m_{p}\right) \cdot g \cdot \operatorname{sign}\left(\dot{x}_{2}\right)-f_{r} \cdot g \cdot\left(m_{31} \cdot \operatorname{sign}\left(\dot{x}_{2}-\dot{x}_{31}\right)+m_{32} \cdot \operatorname{sign}\left(\dot{x}_{2}-\dot{x}_{32}\right)+m_{33} \cdot \operatorname{sign}\left(\dot{x}_{2}-\dot{x}_{33}\right)\right) ; \\
& \left(m_{2}+m_{31}\right) \cdot \ddot{y}_{2}+\mu_{l} \cdot \dot{y}_{2}+\mu_{1 y} \cdot\left(\dot{y}_{2}-\dot{y}_{1}\right)+\left(\mu_{r}+\mu_{2} \cdot \sin (\pi / 3)\right) \cdot\left(2 \cdot \dot{y}_{2}-\dot{y}_{32}-\dot{y}_{33}\right)+ \\
& +c_{1 y} \cdot\left(y_{2}-y_{1}\right)+c_{2} \cdot \sin (\pi / 3) \cdot\left(2 \cdot y_{2}-y_{32}-y_{33}\right)= \\
& =-P \cdot \sin (\omega \cdot t+\pi / 3) \cdot \sin (\pi / 3)-P \cdot \sin (\omega \cdot t+2 \cdot \pi / 3) \cdot \sin (2 \cdot \pi / 3)- \\
& -f_{l} \cdot\left(m_{1}+m_{p}\right) \cdot g \cdot \operatorname{sign}\left(\dot{y}_{1}\right)-f_{r} \cdot g \cdot\left(m_{32} \cdot \operatorname{sign}\left(\dot{y}_{2}-\dot{y}_{32}\right)+m_{33} \cdot \operatorname{sign}\left(\dot{y}_{2}-\dot{y}_{33}\right)\right) \text {; } \\
& m_{31} \cdot \ddot{x}_{31}+\left(\mu_{r}+\mu_{2}\right) \cdot\left(\dot{x}_{31}-\dot{x}_{2}\right)+c_{2} \cdot\left(x_{31}-x_{2}\right)=P \cdot \sin (\omega \cdot t)-f_{r} \cdot m_{31} \cdot g \cdot \operatorname{sign}\left(\dot{x}_{31}-\dot{x}_{2}\right) \text {; } \\
& m_{32} \cdot \ddot{x}_{32}+\left(\mu_{r}+\mu_{2} \cdot \cos (\pi / 3)\right) \cdot\left(\dot{x}_{32}-\dot{x}_{2}\right)+c_{2} \cdot \cos (\pi / 3) \cdot\left(x_{32}-x_{2}\right)= \\
& =P \cdot \sin (\omega \cdot t+\pi / 3) \cdot \cos (\pi / 3)-f_{r} \cdot m_{32} \cdot g \cdot \operatorname{sign}\left(\dot{x}_{32}-\dot{x}_{2}\right) ; \\
& m_{32} \cdot \ddot{y}_{32}+\left(\mu_{r}+\mu_{2} \cdot \sin (\pi / 3)\right) \cdot\left(\dot{y}_{32}-\dot{y}_{2}\right)+c_{2} \cdot \sin (\pi / 3) \cdot\left(y_{32}-y_{2}\right)= \\
& =P \cdot \sin (\omega \cdot t+\pi / 3) \cdot \sin (\pi / 3)-f_{r} \cdot m_{32} \cdot g \cdot \operatorname{sign}\left(\dot{y}_{32}-\dot{y}_{2}\right) ; \\
& m_{33} \cdot \ddot{x}_{33}+\left(\mu_{r}+\mu_{2} \cdot \cos (\pi / 3)\right) \cdot\left(\dot{x}_{33}-\dot{x}_{2}\right)+c_{2} \cdot \cos (\pi / 3) \cdot\left(x_{33}-x_{2}\right)= \\
& =P \cdot \sin (\omega \cdot t+2 \cdot \pi / 3) \cdot \cos (2 \cdot \pi / 3)-f_{r} \cdot m_{33} \cdot g \cdot \operatorname{sign}\left(\dot{x}_{33}-\dot{x}_{2}\right) ; \\
& m_{33} \cdot \ddot{y}_{33}+\left(\mu_{r}+\mu_{2} \cdot \sin (\pi / 3)\right) \cdot\left(\dot{y}_{33}-\dot{y}_{2}\right)+c_{2} \cdot \sin (\pi / 3) \cdot\left(y_{33}-y_{2}\right)= \\
& =P \cdot \sin (\omega \cdot t+2 \cdot \pi / 3) \cdot \sin (2 \cdot \pi / 3)-f_{r} \cdot m_{33} \cdot g \cdot \operatorname{sign}\left(\dot{y}_{33}-\dot{y}_{2}\right) \text {. }
\end{aligned}
$$




\section{Conclusions}

Based on the results of thorough analysis of the existing designs of vibratory lapping machines, the single-mass, double-mass and three-mass design diagrams were considered. The prospects of implementing the hanger-type oscillatory systems were substantiated. The simplest machines designed on the basis of single-mass oscillatory systems allow to perform single-side lapping of flat surfaces. In order to improve the quality and to intensify the process of lapping, it was proposed to excite circular oscillatory motion of laps using several pairs of electromagnets places in a circle of the laps. This idea was implemented in single-mass, double-mass and three-mass designs. In order to investigate the lapping process, the corresponding mathematical models describing the motion of the laps during the treatment were derived. In further investigation on the subject of the paper, there will be deduced the analytical dependencies for calculating inertial, stiffness and excitation parameters of the corresponding oscillatory systems in order to ensure the energy-efficient resonant operation mode.

\section{References}

[1] O. S. Lanets, Ya. V. Shpak, and Yu. P. Sholovii, "Mizhrezonansni vibratsiini prytyralni mashyny z elektromahnitnym pryvodom, rozrobleni na osnovi efektu "Nulovoi zhorstkosti"” ["Inter-Rezonant Vibratory Lapping Machines with Electromagnetic Drive Designed on the Basis of the Effect of "Zero-Stiffness"], Avtomatizaciâ virobničih procesìv u mašinobuduvannì ta priladobuduvannì [Industrial Process Automation in Engineering and Instrumentation], vol. 41, pp. 41-48, 2007. [in Ukrainian].

[2] R. I. Silin, V. V. Tret'ko, and A. I. Gordeev, "Dinamicheskaja model' i ee realizacija v rezonansnom vibracionnom stanke dlja dovodki ploskih izdelij" ["Dynamic model and its implementation in resonant vibration machine for flat articles grinding"], Vektor nauki Tol'jattinskogo gosudarstvennogo universiteta [Vektor Nauki of Togliatti State University], vol. 3-1 (33-1), pp. 123-128, 2015. [in Russian].

[3] V. F. Makarov, and K. R. Muratov, "Analiz oborudovanija dlja finishnoj abrazivnoj obrabotki ploskih precizionnyh poverhnostej izdelij" ["Equipment analysis for finishing abrasive processing of flat precision surfaces of products"], Vestnik Permskogo nacional'nogo issledovatel'skogo politehnicheskogo universiteta. Mashinostroenie, materialovedenie [Bulletin of Perm National Research Polytechnic University. Mechanical engineering, materials science], vol. 19, no. 1, pp. 170-187, 2017. [in Russian].

[4] O. S. Lanets, O. V. Havrylchenko, Ya. V. Shpak, and V. M. Zakharov, "Vibratsiina vykinchuvalna mashyna z elektromahnitnym pryvodom" ["Vibratory finishing machine with electromagnetic drive"], UA Patent 93891, October 27, 2014. [in Ukrainian].

[5] O. S. Lanets, O. V. Havrylchenko, V. M. Zakharov, and V. M. Korendiy, "Vibratsiina vykinchuvalna mashyna z elektromahnitnym pryvodom" ["Vibratory finishing machine with electromagnetic drive"], UA Patent 132950, March 25, 2019. [in Ukrainian].

[6] I. V. Kuzio, O. S. Lanets, O. V. Havrylchenko, V. M. Zakharov, and V. M. Korendiy, "Vibratsiina vykinchuvalna mashyna z elektromahnitnym pryvodom" ["Vibratory finishing machine with electromagnetic drive"], UA Patent 141765, April 27, 2019. [in Ukrainian].

[7] I. V. Kuzio, V. M. Zakharov, V. M. Korendiy, and O. V. Havrylchenko, "Vibratsiina vykinchuvalna mashyna z elektromahnitnym pryvodom" ["Vibratory finishing machine with electromagnetic drive"], UA Patent 142743, June 25, 2019. [in Ukrainian].

[8] O. V. Havrylchenko, V. M. Korendiy, and V. M. Zakharov, "Formuvannia matematychnykh modelei try- i chotyrymasovykh kolyvnykh system vibrovykinchuvalnykh verstativ" ["Formation mathematical model three and four mass oscillatory systems of vibrating finishing machines"], Visnyk Natsionalnoho universytetu "Lvivska politekhnika" [Bulletin of Lviv Polytechnic National University], no. 866, pp. 3-12, 2017. [in Ukrainian].

[9] V. Korendiy, and V. Zakharov, "Substantiation of Parameters and Analysis of Operational Characteristics of Oscillating Systems of Vibratory Finishing Machines", Ukrainian Journal of Mechanical Engineering and Materials Science, vol. 3, no. 2, pp. 67-78, 2017.

[10] I. Kuzio, V. Zakharov, and V. Korendiy, "Substantiation of inertial, stiffness and excitation parameters of vibratory lapping machine with linear oscillations of laps", Ukrainian Journal of Mechanical Engineering and Materials Science, vol. 4, no. 2, pp. 26-39, 2018.

[11] I. V. Kuzio, V. M. Zakharov, and V. M. Korendiy, "Modelling the process of dressing the laps of vibratory finishing machine", Avtomatizaciâ virobničih procesìv u mašinobuduvannì ta priladobuduvannì [Industrial Process Automation in Engineering and Instrumentation], no. 52, pp. 32-42, 2018. 